\title{
FORMACÃO EM GRUPOS NA PERSPECTIVA DE DESENVOLVIMENTO PROFISSIONAL: PROFESSORES EXPERIENTES E INICIANTES DE MATEMÁTICA
}

GROUP EDUCATION FROM THE PERSPECTIVE OF PROFESSIONAL DEVELOPMENT: EXPERIENCED AND NOVICE MATHEMATICS TEACHERS

\section{FORMACIÓN EN GRUPOS DESDE LA PERSPECTIVA DEL DESARROLLO PROFESIONAL: PROFESORES EXPERIMENTADOS Y PRINCIPIANTES DE MATEMÁTICAS}

Renata Prenstteter Gama Doutora em Educação pela UNICAMP. Docente do Programa de Pós-Graduação em Educação da UFSCar.

Programa de Pós-Graduação em Educação Universidade Federal de São Carlos (UFSCar) São Carlos - SP - Brasil

Endereço: Rodovia Washington Luís, Km 235, 310 São Carlos - SP CEP: $13565-905$

E-mail: rpgama@ufscar

\section{RESUMO}

O artigo tem como objetivos descrever e analisar práticas e/ou dinâmicas desenvolvidas no processo de formação contínua de professores de Matemática em grupos na perspectiva de desenvolvimento profissional e identificar as características dos professores experientes e iniciantes nesse processo. Os aspectos teóricos que embasam a problemática do estudo abordam, de um lado, aprendizagens docentes e, de outro, o processo de desenvolvimento profissional docente. Os grupos e os sujeitos foram identificados por meio de questionário inicial. Para aprofundar a pesquisa, tendo por base uma abordagem qualitativa e interpretativa, foram utilizados: entrevistas, observações de aulas e de reuniões dos grupos, registros virtuais e publicações dos grupos e dos iniciantes. Para a análise, foi utilizada a técnica de triangulação dos dados, cruzando-se os dados entre si e, posteriormente, com a literatura. Os resultados apontam que os professores participam de forma distinta e dão contribuições específicas dentro dos grupos em relação à fase da carreira em que se encontram. Os professores iniciantes, normalmente periféricos aos grupos, desempenham um papel importante para novos olhares e para a manutenção das práticas internas.

PALAVRAS-CHAVE: Formação contínua de professores. Desenvolvimento profissional. Grupos colaborativos.

ABSTRACT

This paper describes and analyzes the practices and/or dynamics developed in the process of continuing education of math teachers from a perspective of professional development, and identifies the characteristics 
of both experienced and novice teachers involved in this process. The theoretical aspects underlying this study are related, on one hand, to teachers' learning and, on the other, to their professional development process. The groups and subjects were identified by means of a preliminary questionnaire. In order to deepen the research, which follows a qualitative and interpretive approach, the following tools were used: interviews, notes taken during classes and group meetings, online records, and publications by the groups and the novice teachers. The data triangulation technique was used in the analysis to cross- compare the data, and later, to compare the data with the literature. The results indicate that teachers take part in the process in different ways, and make contributions within the groups according to the stage of their career. Novice teachers, who are usually peripheral to the groups, play an important role in providing new perspectives and maintaining internal practices.

KEYWORDS: Teacher continuing education. Professional development. Collaborative groups.

\section{RESUMEN}

Este artículo tiene como objetivos describir y analizar prácticas y/o dinámicas desarrolladas en el proceso de formación continua de profesores de matemáticas en grupos desde la perspectiva del desarrollo profesional e identificar las características de los profesores experimentados y principiantes en ese proceso. Los aspectos teóricos que fundamentan la problemática del estudio abordan, por un lado, aprendizajes docentes y, por el otro, el proceso de desarrollo profesional docente. Los grupos y los sujetos fueron identificados por medio de un cuestionario inicial. Para profundizar la investigación, con base en un abordaje cualitativo e interpretativo, se utilizaron entrevistas, observaciones de clases y de reuniones de los grupos, registros virtuales y publicaciones de los grupos y de los principiantes. Para el análisis se utilizó la técnica de triangulación de los datos, cruzando los datos entre sí y posteriormente con la literatura. Los resultados señalan que los profesores participan de forma distinta y dan contribuciones específicas dentro de los grupos en relación a la etapa de la carrera en la que se encuentran. Los profesores principiantes, normalmente periféricos a los grupos, desempeñan un papel importante para obtener nuevas miradas y para la manutención de las prácticas internas.

PALABRAS CLAVE: Formación continua de profesores. Desarrollo profesional. Grupos colaborativos.

\section{INTRODUÇÃO}

O objetivo deste artigo é descrever e analisar práticas e/ou dinâmicas desenvolvidas no processo de formação contínua de professores de Matemática em grupos na perspectiva de desenvolvimento profissional e identificar as características dos professores experientes e iniciantes nesse processo. $\mathrm{O}$ artigo está baseado nos resultados de uma pesquisa de doutorado que teve como foco principal de estudo o processo de iniciação à docência e de desenvolvimento profissional, quando o recémformado em Matemática participa de grupos colaborativos.

\section{A FORMAÇÃO DOS PROFESSORES EM ESPAÇOS COLETIVOS E A APRENDIZAGEM DO PROFESSOR}

Os estudos sobre formação de professores, atualmente, têm reconhecido a complexidade da prática docente, o que leva à necessidade do aprender contínuo em um mundo em constantes mudanças. A concepção de aprendizagem docente também tem se alterado ao longo do tempo: não consiste apenas em acúmulo de conhecimentos, mas compõe-se também de apropriações significativas e autogeridas pelo professor.

Considerando essa complexidade, Cochran Smith e Lytle (1999), em relação às aprendizagens do professor para a formação profissional docente, analisam três concepções: "para, na e da" 
prática. A concepção de conhecimento "para" a prática é associada a iniciativas de formação continuada - as mais conhecidas e utilizadas - , englobando escolas e sistemas escolares inteiros. As aprendizagens são baseadas em teorias gerais e em descobertas de pesquisa, as quais os professores são treinados para implantar.

O conhecimento "na" prática fundamenta-se na ideia de que o conhecimento se origina na reflexão e na investigação da prática; a ênfase está no conhecimento em ação, nas reflexões do professor sobre a prática, nas investigações sobre a prática e nas narrativas sobre a prática. Essas iniciativas estão centradas na ajuda aos professores, explorando problemas da prática que não podem ser resolvidos pela aplicação de teorias estabelecidas e pela reconsideração de suas próprias suposições e raciocínios. Nos programas, os facilitadores trabalham muitas vezes com grupos de professores, que funcionam como equipe externa de apoio, levando os outros a questionar suas próprias suposições e reconsiderar as bases de suas ações e de suas crenças.

Da perspectiva do conhecimento "da" prática, os pesquisadores sugerem, para favorecer o desenvolvimento profissional, oportunidades para que os professores explorem e questionem suas (e dos outros) ideologias, suas interpretações e suas práticas. Isto significa que os professores aprendem ao desafiar suas próprias suposições; ao identificar questões importantes da prática; ao propor problemas; ao estudar seus próprios estudantes, salas de aula e escolas; ao construir e reconstruir o currículo; e ao assumir papéis de liderança e de protagonistas na busca da transformação das salas de aula, das escolas e das sociedades.

Podemos perceber que Cochran Smith e Lytle (1999), tanto na segunda perspectiva, de aprendizagem "na", como na terceira, "da" prática, destacam a importância da reflexão dos professores sobre suas práticas. Mas, sobretudo na terceira concepção, apontam para a relevância da pesquisa do professor em comunidades investigativas locais e de uma relação dialética teoriaprática, que acena para a importância de professores constituírem grupos de estudo e adotarem uma postura investigativa e questionadora de suas práticas.

Day (1999, p. 84), considerando a complexidade da prática, afirma que, para os professores continuarem "a desenvolver-se profissionalmente, têm de envolver-se em diferentes tipos de reflexão, na investigação e na narrativa, ao longo de sua carreira, e ser apoiados para enfrentarem os desafios que tal empreendimento implica".

Para Bolzan (2002), a reflexão sobre a prática ganha relevância se for realizada de maneira compartilhada e contínua:

\begin{abstract}
Refletir sobre a prática pedagógica parece ser um dos pontos de partida, pois compreender o processo de construção de conhecimento pedagógico de forma compartilhada implica compreender como se constitui esse processo no cotidiano escolar, local de encontros e desencontros, de possibilidades e limites, de sonhos e desejos, de encantos e desencantos, de atividade de reflexão, de interação e de mediação nessa construção que não é unilateral, mas acontece à medida que compartilhamos experiências, vivências, crenças, saberes, etc. numa ciranda que não se esgota, ao contrário, se desdobra, se modifica, se multiplica, revela conflitos e se amplia. (p. 27).
\end{abstract}

Além disso, no seio de um grupo, a "construção compartilhada de conhecimento favorece a autonomia dos participantes, possibilitando a eles irem além do que seria possível, se estivessem trabalhando individualmente" (BOLZAN, 2002, p. 63). Essa prática, numa visão vygostskiana, pode levar o indivíduo à realização de atividades com mais autonomia, devido ao fato de ter participado de uma atividade colaborativa ou de ter recebido apoio ou estímulo externo.

Fiorentini (2004) justifica que a colaboração e a pesquisa colaborativa vêm ganhando cada vez mais importância, devido aos desafios e aos problemas crescentes da sociedade atual:

\footnotetext{
O trabalho colaborativo e a pesquisa colaborativa, entre professores de diferentes instituições e níveis de ensino, têm surgido no mundo inteiro como uma resposta às mudanças sociais, políticas, culturais e tecnológicas que estão ocorrendo em escala mundial. Mudanças essas que colocam em xeque as formas tradicionais de educação e desenvolvimento profissional e de produção de conhecimentos. (p. 72).
}

No caso dos professores que participam dos grupos de estudos colaborativos, as aprendizagens desenvolvidas são associadas diretamente à dimensão coletiva, pois os grupos de estudo e de reflexão sobre a prática podem ser considerados como pequenas comunidades constituídas por pessoas 
engajadas, nas quais ocorre, mediante participação, um tipo de aprendizagem que Wenger (2001) caracteriza como aprendizagem social. Esta consiste na negociação de significados, na construção e no compartilhamento de conhecimentos, cujo ponto de partida é a prática social.

Wenger (2001) aponta que o tipo de afiliação a uma comunidade de prática depende do compromisso mútuo e vice-versa. As pessoas afiliadas não supõem necessariamente homogeneidade e nem um resultado do desenvolvimento, "cada participante de uma comunidade de prática encontra um lugar e adquire uma identidade própria que vai se integrando e definindo cada vez mais por meio do compromisso da prática" (p. 103). A prática como fonte de coerência da comunidade é a negociação de uma prática conjunta, que inclui aspectos instrumentais, pessoais e interpessoais. Por último, temos o desenvolvimento do repertório comum, com rotinas, palavras, instrumentos, relatos, gestos, símbolos, gêneros, ações e concepções produzidos na comunidade, combinando aspectos de participação e reificação.

Os grupos compartilham saberes docentes de forma contínua e promovem diversos tipos de reflexões, coletivas e/ou investigativas, que podem auxiliar o professor a lidar com inseguranças, ansiedades, percepções da realidade enfrentada, (re)significações ou novos conhecimentos e com o questionamento de pressuposições e de premissas da sua prática docente, sinalizando para a concepção de aprendizado "da" prática (COCHRAN SMITH; LYTLE, 1999).

Tendo por base pesquisas realizadas na Unicamp e estudo desenvolvido pelo Grupo de Estudos e Pesquisa em Formação de Professores de Matemática (NACARATO et al., 2003), Fiorentini (2004) concebe um grupo de trabalho colaborativo como aquele em que a participação é voluntária; há um forte desejo de compartilhar saberes e experiências, inclusive da prática; há momentos de batepapo informal, reciprocidade afetiva e confraternização; os participantes sentem-se à vontade para expressar o que pensam e estão dispostos a ouvir críticas e a mudar; não existe uma verdade ou orientação única; há confiança e respeito mútuos; os participantes negociam metas e objetivos comuns; compartilham significados; há oportunidade de produzir e sistematizar conhecimentos e reciprocidade de aprendizagem.

Nessa problematização e construção teórica do objeto de estudo, temos três dimensões referentes às características dos professores iniciantes, ao desenvolvimento profissional e à reflexão compartilhada.

A primeira dimensão, relativa às características dos professores iniciantes, reconhece a complexidade da prática docente vivenciada pelos professores em início de carreira (até três anos). Essa complexidade gera dificuldades que, na maioria dos professores iniciantes, traduzem-se em sentimentos de insegurança, ansiedade, isolamento, choque de realidade e apresentam aspectos de sobrevivência e descoberta, além do centrar-se em si mesmo. Essas dificuldades estão relacionadas aos altos índices de desistência nos primeiros anos de trabalho e têm originado, em diversos países, programas de apoio.

A segunda dimensão destaca a importância do desenvolvimento profissional e considera a multiplicidade de fatores que participam e interferem ao longo da carreira. Para a presente pesquisa, o desenvolvimento profissional trata de um processo pessoal, interativo, dinâmico, contínuo, evolutivo e sem fim, que envolve aspectos conceituais e comportamentais. As aprendizagens advindas desse processo são de natureza pessoal, profissional, institucional, social e acontecem ao longo da trajetória de vida de cada um. Além disso, o desenvolvimento profissional dos professores depende também das políticas e dos contextos escolares nos quais realizam a sua atividade docente.

A terceira e última dimensão, a reflexão compartilhada, revela que professores na fase inicial da carreira estão ansiosos por aprender o novo ofício. Em relação à aprendizagem dos professores, o processo reflexivo é destacado, sobretudo nas perspectivas "na" e "da" prática e, se realizado de maneira compartilhada e contínua, ganha mais relevância e possibilita ir além do que seria possível nas reflexões individuais. Em especial, a perspectiva "da" prática favorece o desenvolvimento profissional, ao proporcionar oportunidades para que os professores explorem e questionem suas (e dos outros) ideologias, suas interpretações e suas práticas em uma sistemática contínua. Essa perspectiva acena para a importância de os professores constituírem grupos de estudo e adotarem uma postura investigativa e questionadora de suas práticas.

Considerando as dimensões apontadas, a pesquisa tem como hipótese de trabalho o fato de que a participação de professores em grupos colaborativos de estudo representa um fator favorável 
e catalisador do desenvolvimento profissional. Esta foi a razão pela qual optamos por investigar as características dos grupos colaborativos de estudo sobre a prática docente para o desenvolvimentos profissional de professores.

\section{ASPECTOS METODOLÓGICOS DA PESQUISA}

Visando identificar grupos de estudo colaborativos que tivessem professores iniciantes, foi enviado um questionário inicial, por e-mail, a 60 professores de Matemática que lecionavam em seus primeiros anos, no interior do Estado de São Paulo - Brasil. A análise nos permitiu identificar a existência de três grupos colaborativos (Quadro 1).

A pesquisa de natureza qualitativa interpretativa, contou com os seguintes instrumentos de coleta de informações: entrevistas transcritas dos professores e coordenadores dos grupos; observações presenciais de aulas dos professores e de reuniões dos grupos, com a produção de diários de campo; atas e publicações dos grupos; narrativas escritas pelos iniciantes sobre suas práticas docentes; e-mails e registros obtidos do espaço virtual dos grupos.

Embora, no estudo original da tese, tenhamos trabalhado com outras categorias de análise e interpretação, para este artigo, focalizamos apenas as características dos grupos colaborativos no processo de formação do professor de Matemática.

Quadro1: Panorama geral dos grupos colaborativos investigados

\begin{tabular}{|c|c|c|}
\hline GRUPO & CONSTITUIÇÃO DO GRUPO & OBJETIVO DO GRUPO \\
\hline 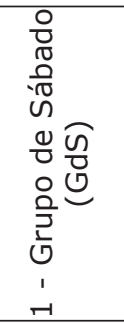 & $\begin{array}{l}\text { GdS - Iniciou em 1999, idealizado } \\
\text { e coordenado por um professor } \\
\text { universitário. Realiza encontros quinzenais } \\
\text { na universidade com professores de } \\
\text { Matemática e das séries iniciais da } \\
\text { rede pública e privada, licenciandos de } \\
\text { Matemática, pós- graduandos e professores } \\
\text { da Faculdade de Educação. }\end{array}$ & $\begin{array}{l}\text { Problematizar, investigar, refletir } \\
\text { e escrever sobre a prática } \\
\text { pedagógica e docente em } \\
\text { Matemática nas escolas e sobre } \\
\text { o processo de desenvolvimento } \\
\text { profissional do professor nesse } \\
\text { contexto. }\end{array}$ \\
\hline 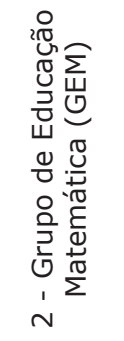 & $\begin{array}{l}\text { GEM - Iniciou em 2003, idealizado } \\
\text { e coordenado por uma professora } \\
\text { universitária. Realiza encontros quinzenais } \\
\text { com professores de Matemática e } \\
\text { das séries inicias da rede pública e } \\
\text { privada, licenciandos de Matemática e } \\
\text { Pedagogia, pós-graduandos e professores } \\
\text { universitários de diferentes universidades. }\end{array}$ & $\begin{array}{l}\text { Desenvolver estudos e pesquisas } \\
\text { compreendendo a formação inicial } \\
\text { e continuada em Matemática; } \\
\text { promover discussões e reflexões } \\
\text { sobre a prática e produzir } \\
\text { conhecimento a respeito da inter- } \\
\text { relação entre desenvolvimento } \\
\text { curricular e formação/ } \\
\text { desenvolvimento docente. }\end{array}$ \\
\hline 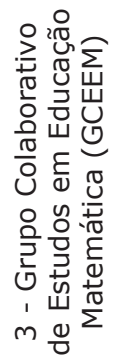 & $\begin{array}{l}\text { GCEEM - Iniciou em 2005, idealizado e } \\
\text { coordenado por uma professora, mestre } \\
\text { em Educação Matemática que leciona na } \\
\text { rede particular e também é efetiva da rede } \\
\text { pública. Realiza encontros quinzenais com } \\
\text { professores de Matemática e das séries } \\
\text { iniciais da rede pública estadual. }\end{array}$ & $\begin{array}{l}\text { Refletir sobre a própria prática } \\
\text { de professores de Matemática e } \\
\text { aprofundar conhecimentos em } \\
\text { Educação. }\end{array}$ \\
\hline
\end{tabular}

\section{O GRUPO COLABORATIVO DE MATEMÁTICA: PROFESSORES EXPERIENTES E INICIANTES}

Ao estudarmos três grupos colaborativos, podemos destacar o potencial das práticas e/ou das dinâmicas vivenciadas pelos professores de Matemática, em especial os iniciantes. Estes desenvolvem um processo de formação contínua em um paradigma que coloca como centro de preocupação o 
desenvolvimento profissional dos docentes, articulado à compreensão e à transformação da prática pedagógica em Matemática nas escolas.

As características desejáveis para uma formação contínua em um contexto de colaboração foram destacadas por Pacheco e Flores (1999) da seguinte forma: "A formação contínua deve potencializar a colaboração dos diversos atores do sistema educativo e a realização de projetos de investigaçãoação-formação orientados para o desenvolvimento profissional do professor" (p. 135).

Nesses grupos colaborativos estudados, podemos perceber a disponibilidade e a abertura para receber diferentes membros que se interessam pela formação e pela qualidade do processo de ensino e aprendizagem de Matemática, o que potencializa a reflexão e o desenvolvimento de diferentes olhares e significações sobre o trabalho e a vida docente. Atualmente, nos grupos participam coordenadores de escola, pós-graduandos, licenciandos, professores universitários e escolares das séries iniciais, do ensino fundamental e médio.

Outra característica dos grupos é a voluntariedade apontada por Fiorentini (2004). Os grupos constituíram-se por iniciativa dos coordenadores - professores universitários e assistente técnica pedagógica -, com o intuito de vivenciar uma prática mais participativa e compartilhada de formação docente e de pesquisa sobre a prática pedagógica em Matemática nas escolas do ensino fundamental e médio, tendo os diferentes atores como parceiros desse processo. Os professores iniciantes também se integraram aos grupos, principalmente, por sentirem necessidade de apoio ou de esclarecimentos para enfrentar os problemas da prática docente e/ou ainda por vislumbrarem ali a oportunidade de formação continuada.

Nesses grupos, como a constituição e a participação não são impostas pela coordenação ou pela instituição de ensino, a voluntariedade é entendida como uma característica vinculada à necessidade dos integrantes de melhorar a prática e a formação docente, sendo o grupo institucionalizado ou não. A necessidade constitui uma condição que favorece o desenvolvimento profissional de todos os participantes, pois "quando a formação não corresponde a uma necessidade sentida pelos professores, é natural que estes perfilhem uma perspectiva que os coloca numa situação passiva, que optem por um paradigma onde tem muito mais a receber do que a dar ou partilhar" (PACHECO; FLORES, 1999, p. 131).

Essas características e a participação no grupo colaborativo conduzem-nos a compreender as interações contínuas realizadas nos encontros, que permitem reflexões e negociações das realidades e das experiências de cada um de forma ativa. Essas negociações de significado supõem, segundo Wenger (2001, p. 78):

1. um processo ativo de produção de significado que é ao mesmo tempo dinâmico e histórico;

2. um mundo de resistência e maleabilidade;

3. a capacidade mútua de influir e ser influído;

4. a intervenção de uma multiplicidade de fatores e perspectivas;

5. a produção de uma nova resolução na convergência destes fatores e perspectivas;

6. o incompleto desta resolução, que pode ser parcial, provisória, efêmera e específica de uma situação.

Cabe pontuar que essas interações contínuas com negociações de significado que acontecem no grupo são características não necessariamente simétricas de participação. No caso dos iniciantes, essas negociações podem ser até silenciosas, pois resultam do compromisso mútuo dos participantes em realizar e compartilhar ações, experiências, ideias e de relacionarem-se entre si. Rogoff (1998), neste mesmo sentido, ajuda-nos a esclarecer melhor esse processo participativo:

Participação requer compromisso em certo aspecto do significado de esforços conjuntos, mas não necessariamente em ação simétrica ou mesmo em conjunto. Uma pessoa que esteja observando ativamente e seguindo as decisões feitas pelos outros está participando, mesmo que ela ou ele venha a contribuir, ou não, diretamente com as decisões à medida que essas são tomadas. (p.130).

Os professores, em início de carreira, estão em uma fase de transição e trazem normalmente dúvidas e inseguranças. Vivenciam outras comunidades e principalmente oscilam entre a comunidade 
de estudantes (licenciandos) e a dos professores de Matemática. Já os professores iniciantes de Matemática desta pesquisa vivenciaram o processo de negociação de significado no grupo e sua entrada nessa comunidade deu-se, inicialmente, de forma periférica. Os grupos situados nas universidades (GdS e GEM) são constituídos por licenciandos, por professores escolares iniciantes e experientes -, por coordenador de escola e por professores universitários. A entrada dos iniciantes investigados em seus grupos não se fez de forma diferente entre os grupos vinculados às universidades e o grupo GCEEM, constituído apenas por professores escolares.

No âmbito dos grupos colaborativos de estudo, está implícita uma concepção diferente de aprendizagem entre peritos e novatos, os quais podem aprender juntos modos de conceber e produzir, de forma compartilhada, novas práticas educativas; ou seja, aprendizagem de conhecimentos "da" prática, sendo este um processo geralmente mediado pela reflexão e pela investigação. Isso acontece porque, segundo Cochran Smith e Lytle (1999), o aprendizado "da" prática tem:

[...] origem no ensino através da investigação ao longo da vida profissional, presumindo que professores iniciantes e experientes precisam participar de trabalhos intelectuais semelhantes. Ao trabalhar juntos em comunidades, tanto os professores novatos quanto os mais experientes apresentam problemas, identificam discrepâncias entre teorias e práticas, desafiam rotinas comuns baseiam-se no conhecimento de outros para construir um enfoque gerativo e tentam tornar visível muito do que é considerado dado no ensino-aprendizagem. (p. 292).

Também pudemos evidenciar que os membros periféricos, professores iniciantes, possuem papel significativo na evolução do grupo, pois podem proporcionar desequilíbrios, com novos olhares sobre a prática interna da comunidade. É importante destacar que a trajetória do iniciante vai em direção de uma participação plena, ocorrendo estranhamentos e identificações, diferentemente dos indivíduos que estão na marginalidade, fenômeno mais frequente entre veteranos, em que há um movimento inverso de saída, de não identificação com a comunidade de prática (WENGER, 2001). As contribuições dos iniciantes para o grupo evidenciam que o professor iniciante é também protagonista no grupo, abrindo espaço para uma (re)significação do conceito e da relação entre experientes e novatos (COCHRAN-SMITH; LYTLE, 1999), pois sempre há aprendizagens mútuas.

Rogoff (1998) também aponta que os novos membros de uma comunidade são ativos em suas tentativas de dar sentido às atividades e podem ser principalmente responsáveis para colocar-se em uma posição de participação. Os processos de comunicação e de coordenação de esforços "com outros membros da comunidade ampliam o entendimento de todos os participantes à medida que eles procuram um campo comum de entendimento para prosseguir com as atividades disponíveis" (p. 130).

Da mesma forma, Bolzan (2002) destaca a importância do coletivo e da interatividade em relação ao conhecimento que:

\begin{abstract}
É gerado e co-construído coletivamente e produzido na interatividade entre duas ou mais pessoas que dele participam, constituindo-se o núcleo da atividade. Assim, as tarefas conjuntas provocam uma necessidade de confrontar pontos de vista divergentes, acerca da mesma atividade, o que possibilita a descentralização cognitiva e se traduz no conflito sociocognitivo que mobiliza as estruturas intelectuais existentes e obriga os sujeitos a reestruturá-las, dando lugar ao progresso intelectual. ( $p$.53).
\end{abstract}

As características desses coletivos fazem emergir a colaboração, considerando que demandam tempo e confiança para que seus integrantes se constituam como participantes colaborativos que respeitam os objetivos individuais e grupais. O coordenador do Grupo de Sábado, ao descrever a evolução do grupo, afirma que este foi, aos poucos, constituindo-se como uma comunidade de prática, conforme conceito de Wenger (2001):

Foi a partir do segundo semestre de existência que o grupo passou a apresentar características de uma comunidade mais ou menos de prática efetiva, mais colaborativa. Foi quando os professores ganharam voz e vez e passaram a determinar o que gostariam de trabalhar. (coordenador GdS, entrevista).

Pacheco e Flores (1999, p. 135) destacam algumas razões culturais que dificultam a constituição de práticas colaborativas entre professores:

Diversos estudos confirmam a existência de uma cultura individualizada, muito longe de uma cultura de colaboração, em que o professor cumpre uma tarefa que lhe está atribuída, não tendo por hábito partilhar as dúvidas, os problemas surgidos no cotidiano escolar. Uma outra concepção de formação contínua só será possível se os professores reconhecerem aos outros professores capacidade de discussão dos problemas que lhes são comuns. 
Cochran-Smith e Lytle (1999), por outro lado, destacam as dinâmicas e as relações de poder próprias de grupos de professores que se reúnem em busca de novas aprendizagens. E para problematizar e compreender esse processo, desenvolveram a noção de "investigação como postura":

A noção de investigação como postura tem como objetivo problematizar os papéis que os professores desempenham no desenho e implementação de iniciativas para seu próprio aprendizado. Quando grupos de professores e outros profissionais se reúnem para aprender, há questões relacionadas à negociação da agenda, à divisão do poder e à tomada de decisões, à representação do trabalho do grupo e à negociação das inevitáveis tensões de propósitos e pontos de vista individuais e coletivos. Estas questões raramente são evidentes, mas estão sempre presentes. Como elas emergem e como são geridas são fatores que ou circunscrevem ou ampliam as possibilidades de que, com o tempo, o trabalho se torne mais produtivo. (p. 295).

Esses aspectos e dinâmicas foram percebidos por nós, nos grupos, que interpretamos que a gestão dos conflitos ou das divergências entre os participantes permite, com o tempo, a emergência de amigos críticos que contribuem para a consolidação das práticas colaborativas. As interações e as negociações de significado pelos diversos atores que compõem o grupo, diferentemente do senso comum, podem ser construídas e proporcionar a produção de conhecimento que demanda práticas com posturas de reflexão e investigação.

Apesar da divisão histórica entre acadêmicos e práticos, que trabalham em culturas e/ou comunidades de prática distintas e respondem a exigências diferentes, nas últimas décadas temse buscado nas parcerias colaborativas a superação dessa distinção e seus aprendizados mútuos. Day $(1999$, p. 235) revela que "há cada vez mais parcerias bem sucedidas ao nível de formação inicial e contínua, particularmente aquelas que se destinam a melhorar as capacidades de criação de conhecimento dos indivíduos e das comunidades profissionais".

Em nossa pesquisa de campo junto aos grupos colaborativos, pudemos identificar algumas práticas e/ou dinâmicas que podem ser consideradas catalisadoras de desenvolvimento profissional dos participantes: coordenação e registros das reuniões presenciais de forma compartilhada e alternada, com diferentes papéis no grupo; estudos teórico-metodológicos definidos a partir das demandas dos participantes; compartilhamento de experiências sobre a prática docente por meio de narrativas orais e escritas; construção coletiva de materiais pedagógicos; publicações de artigos e livros com a participação do grupo; uso de espaço virtual para dúvidas, troca de informações e socialização de material teórico e pedagógico.

Nos grupos estudados, a coordenação e os registros - atas ou memórias - das reuniões são realizados de forma rotativa ou alternada entre os membros do grupo. O cronograma é construído conjuntamente, com sugestões de temas para estudo, incluindo aspectos e materiais teórico-metodológicos.

Fiorentini (2006) destaca que o estabelecimento de rodízio para a coordenação dos encontros contribui para a democratização das relações de poder no grupo e para a divisão de responsabilidades, o que determina características próprias de um grupo autenticamente colaborativo.

Essa colaboração representa um processo do qual cada indivíduo participa, dando sua contribuição num empreendimento comum, cujo resultado beneficia a todas as pessoas envolvidas. Esse processo é compartilhado desde o início, as decisões críticas são tomadas conjuntamente e os recursos e/ou maneira de trabalhar são combinados para atingir os objetivos.

A utilização de narrativas, sobretudo as escritas, tem-se configurado como modo de os participantes compartilharem experiências, seja nas reuniões presenciais, seja nos espaços virtuais. Essas narrativas, que contemplam desenvolvimento de material pedagógico e realização de atividades em sala de aulas, além de reflexões sobre a prática docente, podem ser publicadas em periódicos, congressos ou em livros. Os interesses e as necessidades dos participantes direcionam os estudos teórico-metodológicos e constituem uma estratégia importante que contempla, ao mesmo tempo, interação, sistematização e produção de conhecimento, além de dar visibilidade ao grupo.

Segundo o autor (op.cit.), a participação, pessoal e social oferece a possibilidade de reconhecimento mútuo. A reificação é um termo muito útil para descrever nosso compromisso no mundo como produtores de significados. Etimologicamente, a reificação significa "converter em coisa", mas o termo "abarca uma ampla gama de processos que incluem fazer, desenhar, representar, nomear, codificar e descrever, mas também, perceber, interpretar, utilizar, reutilizar, decifrar e reestruturar" (p. 85). Assim, pode referir-se tanto a um processo quanto a um produto e destinar-se aos dois sentidos, adotando uma grande variedade de formas. 
No caso dos grupos estudados, a reificação manifesta-se mediante apresentações de narrativas em congressos e sua publicação em livros e periódicos e também por meio das atividades aplicadas em sala de aula. Cabe destacar que os itens apontados - participação e reificação - ocorrrem com maior intensidade em alguns momentos e por alguns participantes, pois esses processos são estabelecidos nas trajetórias dos grupos e de seus membros, considerando momentos individuais e coletivos.

\section{CONSIDERAÇÕES FINAIS}

Os grupos colaborativos estudados apresentam como característica comum uma prática coletiva centrada no estudo, na investigação e na reflexão sobre a prática docente em Matemática nas escolas, objetivando a construção de conhecimentos voltados ao desenvolvimento profissional e pessoal dos professores.

Outras características comuns aos grupos são: abertura a uma diversidade de membros; o caráter voluntário, não obrigatório, da participação, a qual é, ao mesmo tempo, individual e coletiva, não necessariamente simétrica ou horizontal, mas com posturas colaborativas. As interações contínuas com negociação de significado são realizadas de forma ativa, respeitando a individualidade, porém tendo abertura no processo de influir e ser influído pelos diversos componentes.

A relação grupal constitui-se com o tempo, requer comprometimento e não contempla uma diferenciação ou uma hierarquia entre experientes e novatos e/ou entre acadêmicos e práticos. No caso dos iniciantes, a característica de participação inicia-se normalmente de forma periférica, oscilante e/ou silenciosa, entretanto possui papel significativo na evolução do grupo ao proporcionar novos olhares sobre a prática interna da comunidade.

\section{REFERÊNCIAS}

BOLZAN, Dóris. Formação de professores: compartilhando e reconstruindo conhecimentos. Porto Alegre: Mediação, 2002.

COCHRAN-SMITH, Marilyn; LYTLE, Susan. Relationships of knowledge and practice: Teacher learning in communities. In: A. Iran-Nejad and C.D. Pearson (Eds.), Review of Research in Education. Washington, DC: AERA.v. 24, p. 251-307, 1999.

DAY, Christopher. Desenvolvimento profissional de professores: o desafio da aprendizagem permanente. Porto - Portugal: Porto Editora, 1999.

FIORENTINI, Dario. Pesquisar práticas colaborativas ou pesquisar colaborativamente. In: BORBA, Marcelo de Carvalho; ARAÚJO, Jussara de Loiola. (Org.). Pesquisa Qualitativa em Educação Matemática. Belo Horizonte: Autêntica, 2004.

FIORENTINI, Dario. Contribuições da reflexão, investigação e escrita em uma comunidade de prática para o desenvolvimento da cultura profissional docente. In: Anais da VII Reunião de didática da Matemática do Cone Sul. Águas de Lindóia, 2006.

NACARATO, Adair Mendes et al. Um estudo sobre pesquisas de grupos colaborativos na formação de professores de Matemática. In: Seminário Internacional de Pesquisas em Educação Matemática, 2., 2003, Santos. Anais...Santos: SBEM, 2003, p.20.

PACHECO, José Augusto e FLORES, Maria Assunção. Formação e avaliação de professores. Portugal: Porto, Porto Editora LDA, Coleção Escola e Saberes, n¹6, 1999.

RODOFF, Bárbara. A natureza cultural do desenvolvimento humano. Tradução Roberto Cataldo Costa. Porto Alegre: Artmed, 2005.

WENGER, Etienne. Comunidades de práctica: aprendizaje, significado e identidad. Colección Cognición y desarrolo humano, no 38. Ediciones Paidós Ibérica S/A. 2001.

Artigo recebido em 13/04/2012

Aprovado em 24/10/2012 